Western University Scholarship@Western

Centre for the Economic Analysis of Property Centre for the Economic Analysis of Property

Rights. Economics and Law Workshop Papers

Rights

1982

\title{
An Economic Theory of Vertical Restraints
}

G. Frank Mathewson

Ralph A. Winter

Follow this and additional works at: https://ir.lib.uwo.ca/economicsceapr_el_wp

Part of the Economics Commons

Citation of this paper:

Mathewson, G. Frank, Ralph A. Winter. "An Economic Theory of Vertical Restraints." Centre for the Economic Analysis of Property Rights. Economics and Law Workshop Papers, 82-19. London, ON: Department of Economics, University of Western Ontario (1982). 
ECONOMICS AND IAW WORKSHOP

82-19

AN ECONOMIC THEORY OF VERTICAL RESTRAINTS

by

G.F. Mathews on and R.A. Winter

4:00 P.m.

Room: 4032 SSC November 4, 1982

Working Papers are preliminary versions of papers circulated on a limited basis for information and discussion. They have not undergone any editorial or refereeing process.

We wish to thank Nancy Gallini, Yehuda Kotowitz, Marty Perry and Steve Salop for helpful comments.

(C) 1982 by G.F. Mathewson and R.A. Winter

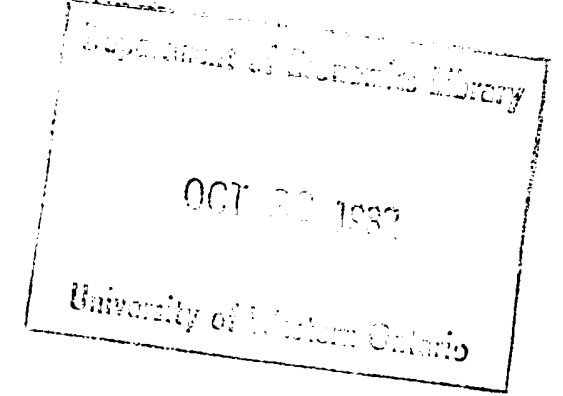

Major funding for the Centre for Economic Analysis of Property Rights has been provided by the Academic Development Fund, The University of Western Ontario. Additional support has come from The Bureau of Policy Coordination, Consumer and Corporate Affairs. The views expressed by individuals associated with the Centre do not reflect official views of the Centre, The Bureau of Policy Coordination, or The University of Western Ontario.

Subscriptions to the Workshop papers and the Working Paper Series are $\$ 40$ per year for institutions and $\$ 25$ per year for individuals. Individual copies, if available, may be purchased for $\$ 3$ each. Address all correspondence to John Palmer, Centre for Economic Analysis of Property Rights, The University of Western Ontario, London, Ontario, CANADA N6A 5C2. 


\section{ABSTRACT}

Vertical restraints on retail price, retail market size, and retail sales, as well as the payment of franchise fees, imposed in contracts by manufacturers with retail firms represent a puzzling and contentious departure from the simple linear-price contracts of anonymous spot markets. In this paper, we analyze both the theoretical rationale for these restrictive contractual clauses and the manner in which the restrictions are packaged fo form jointly efficient (profitable) contracts. Retailers are imperfect competitors with differential products but subject to open entry; manufacturers have monopoly power. In this setting, these restraints internalize several externalities to co-ordinate the incentives of retailers with the profit-maximizing objectives of the manufacturer. Our results suggest that the asymmetry between price and non-price restraints present in existing U.S. legislature is inappropriate. 


\section{Introduction}

Observed agreements between manufacturers and retailers frequently differ markedly from the linear-price contracts of anonymous spot markets usually assumed in economic models. Many wholesale market contracts impose vertical restraints on retailers that can include restrictions on retailer pricing, output and location decisions. Such restraints have been a puzzle to economists, a source of contention in anti-trust legislative and relatively unexplored in economic theory. This paper redresses this imbalance by offering some theoretical results in the use of these restraints by manufacturers.

In particular, we focus on the following retail restraints:

(i) resale price maintenance (RPM) where the manufacturer imposes a price floor in retailers. ${ }^{1}$

(ii) territorial protection, which in the extreme form of closed territory distribution (CTD), is the assignment to each retailer of exclusive rights to all consumers within a territory.

(iii) quantity forcing where the manufacturer requires the retailer to sell a minimum volume of product.

(iv) franchise fees, or non-linear pricing, where retailers pay a fixed fee to the manufacturer to carry the manufacturer's product.

The confusion on the appropriate public policy towards such vertical restraints, exemplified in the variation in legislature in this area, ${ }^{2}$ flows in part from the absence of any satisfactory economic analysis of the incentives for the use of these restraints. If manufacturing and retailing markets were perfectly competitive, these restrictions would not be used. The competitive price system alone would be sufficient to coordinate the retailers' output decisions with the manufacturers interests. 
At the competitive wholesale price, a manufacturer would be content to sell to all willing buyers without restrictions on the re-sale prices or locations. Why, then, are these restrictions observed?

The answer is that the conditions of many retail markets are not consistent with perfect competition. In particular, this paper analyzes vertical restraints in the simplest model incorporating two characteristics of many actual retail markets - these markets are spatially differentiated and retailers have a role in informing consumers about products. In this setting vertical restraints emerge as devices in efficient wholesale contracts, i.e., as devices necessary for the maximization of joint profits of a manufacturer (with some price-setting power) and retailers.

Our analysis turns on the identification of three externalities at the retail level and identifies under alternative conditions the various packages of vertical restraints that are efficient to neutralize these externalities. One implication of this integrated analysis of vertical restraints is that retail price and territorial restrictions can be substitute instruments, used by the manufacturer to achieve the same equilibrium. As a consequence, the current asymmetry in the legal treatment of these restraints under the U.S. law - where price restraints are per se illegal while territorial restraints are subject to a rule of reason - appears to be inappropriate.

Section 2 of this paper sets out the basic assumptions of our model and outlines the market equilibrium in the absence of restraints. Section 3 documents the failure of the linear price system to co-ordinate agents incentives (Proposition 1). Section 4 characterizes the efficient contracts or sets of restraints that emerge as a market response to this failure (Propositions 2 through 8 , as summarized in Table 1). Finally, Section 5 offers our summary and conclusions. 
2. The Basic Model

\section{$2.1 \quad$ Assumptions}

At the outset, we define the complete set of assumptions used in this paper, even though some are inoperative for the moment. We consider a retail market for a product under the following assumptions, some of which are standard in the spatial literature: ${ }^{3}$

(A1) Consumers are uniformly distributed with density $v$ along a circle or a line of infinite length.

(A2) Consumers have a common travel cost $t$ per unit distance, per unit quantity purchased.

(A3) Retail outlets buy at a wholesale price $P_{W^{*}}$ Each incurs a fixed (but not sunk) cost $F$ and no variable costs other than the wholesale price. 4

(A4) A consumer must be informed of the existence of the product before buying.

(A5) Information on the product's existence is provided locally only by the retail firms. Product characteristics are readily verifiable by consumers prior to purchase so that there is no opportunity to induce consumer misperceptions. Information disseminated by a retail firm takes the form of advertising messages or sales effort through local sales personnel (all labelled as advertising from here on) with a constant density over a chosen market area. The total cost of advertising at a density $A$ over at interval ds is bAds. 
(A6) If the density of advertising at a particular location is $A$, then the proportion of consumers informed at that location is a function $h(A)$. The number of consumers informed at each location is $v h(A)$.

(A7) A proportion a of the advertising messages disseminated by any retail outlet reaches consumers outside the outlet's market area. 5

(A8) Once informed of the product's existence, the consumers have access at zero cost to information on the prices and locations of all retail outlets.

(A9) The average demand per informed consumer is $f(P+t s)$ where $P$ is the retail price paid by the consumer (called the "mill" price) and $s$ is the distance travelled to the outlet. (That is, $f$ represents a distribution of reservation prices across consumers at any location). Each consumer buys one unit of product from the outlet whose "delivered" price ( $P+t s$ ) is the lowest (even if informed of the product by a different outlet).

(A10) There is free entry into the retail market so that outlets continue to enter the retail market until profits are driven to zero. and (A10) mean that a retail equilibrium is Chamberlinian.

(A11) Existing retail outlets locate symmetrically in the retail market.

(A12) The wholesale market is supplied by a monopolist who incurs a constant cost of product $c$, and maximizes profit per distance. The manufacturer incurs no transportation costs in distributing the products to outlets. 
(A13) The manufacturer can neither advertise directly nor without prohibitive costs monitor the retailers' levels of advertising. ${ }^{6}$ These excessive monitoring costs foreclose direct contractual control of retailer advertising by the manufacturer.

(A14) Vertical integration into the retail market by the manufacturer is costly. This assumption is reasonable for markets where the entrepreneurial capacity of the manufacturer exhibits diminishing productivity (Friedman 1976, ch.5) or where any of the costs of vertical integration discussed by Williamson (1975: 115-132) are positive.

We start by defining the equilibrium in the retail market for a given wholesale price set by the manufacturer, i.e., the non-integrated equilibrium. This sets the standard of comparison to analyze the use of vertical restraints. Do these constraints improve the manufacturer's profits relative to the non-integrated equilibrium? At the beginning, we focus on the case for vertical restraints in the absence of informational spillovers at the retail level (i.e., $\alpha=0$ ); a subsequent section analyzes vertical restriction in the presence of those spillovers. In both cases, any retail equilibrium depends on the assumed conjectures that retailers hold about the actions of their rivals. We consider two alternative conjectural possibilities:

(A15a) Nash Conjectures (Hotelling-Smithies Competition): Each retail outlet assumes its neighbours' prices to be invariant to its price changes. 7

(A15b) Loschian Conjectures: Each outlet assumes that its market area is invariant to changes in its pirce; equivalently, each outlet assumes that neighbouring outlets will match its price changes. 
Spatial competition theory most commonly uses the Loschian conjectures. Both (A15a) and (A15b) are useful here as together they provide a reasonable range for conjectural assumptions. Some of our results that follow can be explained only under non-Loschian conjectures. An equilibrium in the retail market consists of a retail price, a market radius and a level of advertising for each retail outlet such that each outlet maximizes its profits given its conjectures and earns zero profits (see Figure 1). ${ }^{8}$

\subsection{Retail Market Equilibrium for a Given $P_{w}$ - No Spillovers}

Consider first the Nash equilibrium. A firm setting price $P_{j}$, advertising density $A_{j}$ and serving consumers within a radius $R_{j}$ faces demand defined by:

$$
q\left(P_{i}, A_{j}, R_{j}\right) \equiv 2 v h(A) \int_{0}^{R_{i}} f\left(P_{j}+t s\right) d s
$$

Define $x$ as the distance from the firm $i$ to its neighbours and let $P$ be the price of its neighbouring rivals. Under Nash conjectures, $R_{i}$ is endogenous. It is determined by the condition that a consumer located at the boundary of the market area served by $i$ be indifferent buying from $i$ at $P_{i}$ and buying from the neighbour at $P$ :

$$
\begin{aligned}
P_{i}+t R_{i} & =p+t\left(x-R_{i}\right) \quad \text { or } \\
R_{i} & -\left(P-P_{i}\right) / 2 t+x / 2
\end{aligned}
$$

The substitution of (3) into (1) shows the variability of $q$ in response to $P_{1}$. With abuse of notation, this substitution yields:

$$
q\left(P_{j}, A ; P, x\right)=2 v n(A) \int_{0}^{\left(P-P_{j}\right) / 2 t+x / 2} f\left(P_{j}+t s\right) d s
$$


From (4), the profit of a retail outlet denoted as $\pi^{R}$ is given by

$$
\pi^{R}\left(P_{i}, A_{i} ; P, x\right)=2 v h(A)\left(P_{j}-P_{w}\right) \int_{0}^{\left(P-P_{j}\right) / 2 t+x / 2} f\left(P_{j}+t s\right) d s-2 R b A-F
$$

For a given $P_{W}$, the Nash retail market equilibrium $(P, R, A)$ is determined by a profit-maximizing condition on the retail price $P_{j}$ and the advertising density $A_{i}$, the zero-profit condition on retailers (equation (5) set equal to zero) and symmetry on prices, advertising and locations $\left(P_{i}=P, A_{i}=A, R=x / 2\right)$. We catalogue here these three marginal conditions:

$$
\begin{gathered}
\left.\frac{\partial \pi^{R}}{\partial P_{i} \mid P_{i}=P, R=x / 2=2 v h(A)\left\{\left[\int_{0}^{R} f^{\prime}(P+t s) d s-f(P+t R) / 2 t\right][P-P\right.}\right] \\
\left.+\int_{0}^{R} f(P+t s) d s\right\}=0 \\
\frac{\partial \pi^{R}}{\partial A} \mid P_{i}=P, R=X / 2=2\left\{\left[v\left(P-P_{W}\right) \int_{0}^{R} f(P+t s) d s\right] h^{\prime}(A)-R b\right\}=0 \\
2\left[v h(A)\left(P-P_{W}\right) \int_{0}^{R} f(P+t s) d s-R b A\right]-F=0
\end{gathered}
$$

Consider next the Loschian equilibrium. Under Loschian conjectures, each retail outlet believes either $d R_{j} / d p_{j}=0$ in calculating $d q / d p_{i}$ from (1) or equivalently $d p / d p_{j}=1$ in calculating $d q / d p_{j}$ from (4). That is, if changes in $P_{i}$ are perceived to be matched by changes in $P$, then the boundary of firm i's market area is perceived to remain unaltered. The retail equilibrium in this case is determined by equations (7). (8) and (9) (the conditions on $A$ and zero retail profits are unchanged): 


$$
\frac{\partial \pi^{R}}{\partial P}=2 v h(A)\left[(P-P) \int_{0}^{R} f^{\prime}(P+t s) d s+\int_{0}^{R} f(P+t s) d s\right]=0
$$

We next develop the retail market preferred by both a vertically integrated firm and a non-integrated upstream manufacturer serving a free-entry (zero-profit) retail market. For the vertically integrated firm, profit per unit distance is

$$
\pi(R, P)=[\operatorname{vh}(A) q(P, R)(P-C)-F] / 2 R-b A
$$

where $c$ represents (constant) per unit costs. For the non-integrated manufacturer, profit per unit distance is a function of $P_{w}, P, R$ and $A$. With abuse of notation,

$$
\Pi\left(P_{W} ; P, R . A\right) \equiv \operatorname{vh}(A) q(P, R) \cdot\left(P_{W}-C\right) / 2 R
$$

If the $(P, R, A)$ of (11) are established in a free-entry retail market, then the zero retail-profit condition (8) can be used to eliminate $P_{W}$ from (11), which leaves profits as exactly the function of $(P, R, A)$ described by (10). That is, (10) is not only the profit of a vertically integrated firm for values of $(P, R, A)$ but also the profit of an upstream manufacturer as a function of the "target" variables in the downstream equilibrium conditional on a free-entry (zero-profit) retail market. Define $\left(P^{*}, R^{\star}, A^{*}\right)$ to be the "first-best" equilibrium for the manufacturer. We catalogue here the three "first-best" conditions:

$$
\begin{aligned}
& \frac{\partial \pi}{\partial P}=v h(A)\left[(P-c) \int_{0}^{R} f^{\prime}(P+t s) d s+\int_{0}^{R} f(P+t s) d s\right] / R=0 \\
& \frac{\partial \pi}{\partial R}=\operatorname{vh}(A)(P-c)\left[R f(P+t R)-\int_{0}^{R} f(P+t s) d s+F\right] / R^{2}=0
\end{aligned}
$$




$$
\frac{\partial \Pi}{\partial A}=v^{\prime}\left[(P-c) \int_{0}^{R} f(P+t s) d s\right] / R-b=0
$$

\subsection{Retail Market Equilibrium for a Given $P_{W}$ - Spillovers}

When a proportion $\alpha$ of the advertising messages of each outlet spill over into the market areas of other outlets (A7), retailers benefit from the advertising of other retail competitors, but do not appropriate the full benefits of their own advertising. With these spillovers, the retail profit function (5) is replaced by

$$
\begin{aligned}
\Pi^{R}\left(P_{i}, A_{i} ; P, A, x\right) & =2 v h\left(\alpha A+(1-\alpha) A_{j}\right) \cdot\left(P_{i}-P_{w}\right) \int_{0}^{\left(P-P_{j}\right) / 2 t+x / 2} f\left(P_{i}+t s\right) d s \\
& -2 R b A_{i}-F
\end{aligned}
$$

The only change in (15) from (5) involves the argument of $h(\cdot)$. The zero-profit condition remains unchanged and because changes in advertising cause only iso-elastic shifts in demand, the first-order condition on the retail price remains unchanged as well; the only change in the equilibrium conditions is the replacement of (7), the first-order condition on advertising, by

$$
2\left\{\left[v\left(P-P{ }_{W}\right) \int_{0}^{R} f(P+t s) d s\right] h^{\prime}(A) \cdot \alpha-R b\right\}=0
$$

As spillovers do not affect the total demand for the manufacturer's product, the conditions that determine the first-best (integrated) equilibrium for the manufacturer $((12),(13)$ and (14)) remain unchanged.

Does the manufacturer need to integrate to achieve $\left(P^{*}, R^{*}, A^{*}\right)$ 
first-best outcome for the manufacturer with or without spillovers? The non-integrated manufacturer obviously has the wholesale price $P_{W}$ available as an instrument. Is it alone sufficient? If it is not, then spotmarket contracts alone are inadequate to achieve the profit-maximizing solution. In this case, there is a need for either vertical integration or additional vertical restraints. Before we proceed to the analysis and interpretation of these restrictions, a few definitions will prove helpful. From this choice of vertical restraints, a "minimally sufficient set" of restraints is a minimal set which together with the wholesale price can implement the integrated outcome for the manufacturer. Instruments are substitutes when they are capable of achieving identical target sets $(P, R, A)$. In the presence of such substitute instruments, the minimal efficient set of restraints is not unique. For any set chosen by the manufacturer, each instrument is set to maximize the profits accruing to the manufacturer.

\section{Insufficiency of $P_{W}$ Alone: The Incentive for Integration or Restraints}

Is the wholesale price alone sufficient to achieve $\left(P^{\star}, R^{\star}, A^{\star}\right)$ ? The answer is no. In general, the target set that can be attained with $P_{W}$ alone is a one-dimensional manifold in $(P, R, A)$ space. If conjectures are Nash (Loschian), this manifold is defined by the two equations that result from eliminating $P_{W}$ from $(6),(7)$ and $(8)((7),(8)$ and (9) respectively). These two equations become constraints for the non-integrated manufacturer and with the use of $P_{W}$ alone, the non-integrated monopolist selects $(P, R, A)$ to maximize $\Pi(P, R, A)$ subject to these constraints. Denote the resulting solutions respectively as $\left(P_{N}, R_{N}, A_{N}\right)$ for 
Nash conjectures and $\left(P_{L}, R_{L}, A_{L}\right)$ for Loschian conjectures. Prior intuition suggests that there is a negligible probability that either of the respective one-dimensional feasible sets will pass exactly through $\left(P^{\star}, R^{\star}, A^{*}\right)$. In fact, the feasible sets never contain this first-best point. This proposition registers the failure of spot markets.

Proposition 1: At $\left(P_{L}, R_{L}, A_{L}\right), \pi_{P}<0$ and $\pi_{A}>0$; at $\left(P_{N}, R_{N}, A_{N}\right)$, $\Pi_{A}>0$. Therefore, the non-integrated downstream Loschian retail market sets a price that is too high and both retail markets advertise too little from the perspective of the upstream manufacturer.

Proof: The proof follows from inspection of the correct sets of firstorder conditions. For the non-integrated manufacturer $P_{w}>c$ whatever the nature of the retail conjectures. Therefore, (6) and (7) for $\alpha=0$ (alternatively (6) and (16) for $\alpha>0$ ) imply that the left-hand side of (12) is negative at $\left(P_{L}, R_{L}, A_{L}\right)$ and the left-hand side of (14) is positive evaluated at either $\left(P_{L}, R_{L}, A_{L}\right)$ or $\left(P_{N}, R_{N}, A_{N}\right)$. Given second order conditions, the proposition follows.

At the source of these effects are a set of three externalities. In setting $P_{i}$ and $A_{i}$, the retail firm does not appropriate the additional increment in profits that flows to the upstream manufacturer through the $\left(P_{w}-c\right)$ margin, when $P_{i}$ is lowered or $A_{i}$ is raised. In fact, this extends to any action of the retailer that affects demand. The effect in terms of retail price alone with a manufacturer and retailer, both having price-setting powers, is the double marginalization of Spengler (1950). This vertical externality works to increase $P_{i}$ and to reduce $A_{i}$ relative to the levels for the efficient manufacturer-retailer contract. 
The inadequacy of the retailer's incentive to advertise under these conditions is compounded by the horizontal externality present with spillovers (when $\alpha>0$ ); the retailer does not consider the informational gains to other outlets when setting $A_{j} \cdot 9$

For the non-integrated Nash retailer, a horizontal pecuniary externality affects the pricing decision in a way that offsets the impact of the vertical non-appropriability. In raising the retail price under Nash conjectures, a retailer would confer positive benefits on his neighbours, through the positive cross-elasticity in demand between neighbouring firms. The non-appropriation of these benefits by the Nash retailer reduces his incentive to raise the retail price, compared to the integrated retail market. 10 Therefore, there are warring effects in retail prices from the horizontal pecuniary and the vertical externalities. The net impact of these two externalities may leave retail prices in the non-integrated Nash market too low or too high from the manufacturer's viewpoint. We cannot tell which affect dominates.

The Loschian retailer, in contrast, believes that his neighbours change their prices to match any change in his own prices and therefore, that his neighbours impose upon him a positive pecuniary externality exactly equal to the pecuniary externality that his price changes imposes upon them, i.e., the pecuniary conjectural externalities among retailers are offsetting. This horizontal pecuniary externality is thus internalized when conjecturers are Loschian, leaving only the vertical externality and retail prices which are consequently higher than the manufacturer would prefer. In sum, both the Nash and Loschian markets underadvertise and the Loschian market over-prices from the manufacturer's perspective. 


\section{The Role of Vertical Restraints}

One response of the manufacturer to the inadequacy of spot markets in co-ordinating the incentives of the retailers with his own best interests might be formal integration into the retail market. As we argue in (A13) however, vertical integration may involve costs. If incentives can be harmonized perfectly through the alteration of simple spot-market contracts to include vertical restraints, these costs can be avoided and first-best profits realized for the manufacturer.

We rule-out here direct manufacturer control of local advertising. If such control were possible, the contract would be straight-forward. First, set $A^{*}$ and an administered retail price $P^{*}$ (RPM). Then offer this contract to all takers, i.e., to the infinitely elastic supply of potential entrants into the retail market. With $\left(P^{*}, A^{*}\right)$ specified through such a contract, the zero retail-profit condition could be determined as $P_{W}(R)$. Consequently, knowledge of $R^{*}$ would permit in this case a definition of $P_{w}^{*}$ so that the optimal number of firms would enter the retail market, and the first-best equilibrium would be established.

The vertical restriction on the level of retail-sales effort or advertising may be impossible to enforce, however, because of prohibitive monitoring costs for the manufacturer. Even if manufacturers were to specify target advertising expenses, the costs of manufacturers monitoring directly dealer advertising performance would appear to be substantial. The assumption (A13) that advertising cannot enter as a parameter in the retailer-manufacturer contract is therefore reasonable. Under this assumption, to elicit the first-best optimum $\left(P^{*}, R^{\star}, A^{*}\right)$, vertical restraints must co-ordinate indirectly the retailers' incentives for local advertising 
or sales effort with those of a vertically integrated firm. For example, the most important advertising input for durable-goods dealers (automobiles, stoves, refrigerators, T.V.'s, bicycles) may be sales personnel whose efficient direction requires local control. Consequently, it is not surprising that many important U.S. cases on vertical restrictions involve such durable goods manufacturers (Scherer 1980: 586-594). Since spot markets fail to achieve maximum (first-best profits for the manufacturer in our model), the question is: How do vertical restraints remedy this failure? We proceed to answer this question through a set of propositions that define minimally sufficient sets of instruments. Table 1 presents a summary listing of these minimally sufficient sets of instruments for the manufacturer that we develop in the next set of propositions.

\subsection{Sufficient Restraints: No Advertising Spillovers $(\alpha=0)$}

In general with a three-dimensional target space, intuition suggests the need for three instruments, $P_{w}$ and two additional restraints from the menu of options outlined above. This turns out not to be the case. In fact, $P_{W}$ and franchise fees alone are sufficient to achieve the firstbest solution for the manufacturer when there are no advertising spillovers.

With the addition of franchise fees, the feasible target set extends to a two-dimensional manifold. The fixed franchise fee $G$ enters the zero-profit retail condition to yield:

$$
2 v h(A)(P-P) \int_{0}^{R} f(P+t s) d s-2 R b A-F-G=0
$$

When the retail firms have Loschian conjectures, eliminating $P_{W}$ and $G$ from the equilibrium conditions $(7),(9)$ and (15) yields the single constraint 
determining the target set attainable with $\left(P_{W}, G\right)$. In fact, this constraint is not binding; the two-dimensional manifold contains $\left(P^{*}, R^{\star}, A^{*}\right)$.

Proposition 2: When the retail conjectures are Loschian and there are no advertising spillovers $(\alpha=0)$, the wholesale price and a franchise fee constitute a minimally sufficient set of instruments. The wholesale price is set equal to the constant unit production costs, an efficient transfer price, and all rents are collected by the manufacturer through the franchise fees.

Proof: Set $P_{W}=c$ and let $G^{*}$ solve (15) for $\left(P^{*}, R^{*}, A^{*}\right)$ with $P_{W}=c$. Inspection reveals that the $P$ and $A$ first-order conditions for the Loschian retailer $((17)$ and $(9))$ then coincide with those for the integrated monopolist $\left((12)\right.$ and (14)). Therefore, setting $P_{W}=c$ and $G=G^{\star}$ means that $\left(P^{\star}, R^{\star}, A^{*}\right)$ defined by (12), (13) and (14) satisfy (7), (9) and (15).

The key to this result is that franchise fees provide a channel through which the manufacturer can collect rents once the vertical externality - the only externality present with Loschian retailer conjectures is internalized with the closing of the $\left(P_{W}-c\right)$ wedge. In contrast to the collection of rents through the wholesale price mark-up, franchise fees as a lump-sum instrument are an incentive-neutral channel, i.e., they do not affect any retailer's pricing and advertising incentives.

Proposition 2 is a standard result in non-linear pricing, or more generally in Principle-Agent Theory. When the efficient variable price in the non-linear price schedule $\left(G, P_{W}\right)$ is equal to the marginal production 
costs, the agent (retailer) bears the full costs and benefits of his actions ex-post to the signing of the contract. However, if retail demand were uncertain - and not perfectly correlated across retail locations so that the manufacturer had a potential role in pooling risk - the optimal $P_{W}$ would be greater than $C$ and the fixed fee $G$ would be relatively lower. The manufacturer would absorb some of the uncertainty in demand through the $\left(P_{W}-c\right)$ mark-up. In this case, the optimal contract would (as usual) balance the marginal benefits of this ex-ante risk sharing with the marginal benefits of ex-post efficiency in retailers' incentives.

In Proposition 2, only the vertical externality is at work and one instrument (in addition to $P_{W}$ ) is sufficient. When the horizontal pecuniary externality (discussed above) is introduced through a relaxation of the assumption of Loschian conjectures, an additional instrument becomes profitable:

Proposition 3: When retail conjectures are not Loschian and there are no advertising spillovers $(\alpha-0)$, then the wholesale price, franchise fees and closed territory distribution (CTD) constitute a minimally sufficient set of instruments.

Proof: CTD imposes Loschian conjectures on retailers, whatever their current conjectures. The sufficiency of this set of instruments and the necessity of franchise fees follows immediately from Proposition 2. The necessity of CTD may be illustrated with Nash conjectures for retailers. In this case, a first-best $P_{W}$ must satisfy (6) and (7) (Nash first-order conditions on price and advertising respectively) simultaneously to yield $\left(P *, R^{\star}, A^{*}\right)$. The only $P_{W}$ satisfying (7) leading to first-best advertising 
results is $P_{W}=c$. However, at $\left(R^{*}, A^{*}\right), P_{W}=c$ leads to $P<P^{*}$ from (6) since the left-hand side of $(6)$ is then less than the left-hand side of (12) and is decreasing in $P$ because appropriate second-order conditions are fulfilled. Therefore, franchise fees alone are not sufficient. $\square$

This proposition extends the previous proposition by using CTD to impose Loschian conjectures on retailers whatever their current conjectures. If CTD's were not imposed and manufacturers set efficient transfer prices to obtain optimal local advertising from retailers, Nash retailers would set retail prices that were too low given their excessive estimates of local price elasticities. Therefore, CTD's are both necessary and sufficient.

In this case, by fixing retail territories, CTD's transform nonLoschian into Loschian retailers causing them to reduce their price elasticities to follow optimal monopoly rules for retail prices. Fixed franchise fees are, as before, an optimal vehicle for transferring rents back to the manufacturer as they permit the manufacturer to set efficient transfer prices. Then, the Loschian retailer sets the optimal retail price level.

The empirical facts are that franchisees usually receive simultaneously some form of territorial protection instead of competing freely with all potential entrants, (Caves and Murphy 1976: 572), so that franchise fees and CTD's are empirically complementary instruments. Our analysis offers one explanation for these observed institutional facts.

However, franchise fees are not the only restraint we observe in practice. The essential vertical restraint in some markets such as automobile franchising is that dealers are required only to accept, at the manufacturer's wholesale price, minimum quantities of cars each year (a 
practice labelled as forcing) perhaps with exclusive franchises (White 1971: 151). These levels of sales are beyond the dealer's profit-maximizing quantities. Currently, the forcing restraint is usually the only requirement made of the dealers. For example, franchises for the accepted franchisees do not carry any franchise fees and effective resale price maintenance has appeared only periodically in automobile distribution. (The details appear in white 1971: 136-170.) The decision by automobile manufacturers to invoke only the single restraint may illustrate the somewhat surprising case (Proposition 4 below) that forcing alone can be a sufficient restraint.

When the upstream manufacturer sets a minimum quantity $\hat{q}$ that each retailer must purchase, the retailer's objective is to maximize $\Pi\left(P_{j}, A_{j} ; P, A, x\right)$ subject to

$$
q(P, A ; P, A, x) \geq \hat{q}
$$

when this constraint is binding (as is the case for automobile dealers), the retail price $P$ and advertising level $A$ that solve the maximization under symmetry are determined by (18) and the following first-order condition:

$$
\frac{\partial \pi^{R} / \partial P}{\partial \pi^{R} / \partial A}=\frac{\partial q / \partial P}{\partial q / \partial A}
$$

(In (19), $\partial q / \partial P, \quad \partial \pi^{R} / \partial A<0 ; \quad \partial \pi^{R} / \partial P, \quad \partial q / \partial A>0$.)

Proposition 4: When conjectures are Loschian and there are no advertising spillovers $(\alpha=0)$, forcing is a sufficient restraint. 
Proof: Set $q=q\left(P^{*}, R^{*}, A^{*}\right)$ and set $P_{W}$ to satisfy (8) (zero profits) at $\left(P^{*}, R^{\star}, A^{*}\right)$. To show that $\left(P^{*}, R^{*}, A^{*}\right)$ is an equilibrium, it is sufficient to show that (19) is satisfied. Then, $\left(P^{*}, R^{*}, A^{*}\right)$ is determined by the equilibrium conditions (8), (18) (as an equality) and (19). From (4) and (5), it follows directly that $\partial{ }^{R} / \partial P=\partial q / \partial P \cdot\left(P-P P_{W}\right)+q$ and $\partial \pi^{R} / \partial A=\partial q / \partial A \cdot\left(P-P_{w}\right)-b$. Hence

$$
\frac{\partial \pi^{R} / \partial P}{\partial \pi^{R} / \partial A}=\frac{\partial q / \partial P \cdot\left(P-P_{W}\right)+q}{\partial a / \partial A \cdot\left(P-P_{W}\right)-b}
$$

The integrated first-order conditions (12) and (14) yield

$$
-q / b=\frac{\partial q / \partial P}{\partial q / \partial A}
$$

(21) and (22) together imply (19). ם

Given our previous use of CTD's to force Loschian conjectures on non-Loschian firms, an immediate corollary of Proposition 4 is:

Proposition 5: When conjectures are non-Loschian and there are no spillovers, a minimally sufficient set of restraints is closed territory distribution and forcing.

Proof: The sufficiency of closed territory distribution and forcing follows from Proposition 4. To prove that closed territory distribution is necessary, note that $\partial q\left(P_{i}, A_{i} ; P, x\right) / \partial P$ is less for the Nash than for the Loschian retailer. Therefore, since (22) is satisfied for the Loschian firm at $\left(P^{*}, R^{\star}, A^{*}\right), \quad-q / b>(\partial q / \partial P) /(\partial q / \partial A)$ at $\left(P^{\star}, R^{\star}, A^{*}\right)$ for the 
Nash outlet which in turn implies that $\left[\left(\partial \pi^{R} / \partial P\right) /\left(\partial \pi^{R} / \partial A\right)\right]<[(\partial q / \partial P) /(\partial q / \partial A)]$ at $\left(P^{\star}, R^{\star}, A^{\star}\right)$ for retailers with Nash conjectures. As a consequence, forcing alone is not sufficient when retailer conjectures are Nash. The necessity of forcing in this case, given closed territory distribution, follows from Proposition 1. Hence, forcing and closed territory distributions are a minimally sufficient set of restraints.

It is useful here to comment on the economic intuition behind this forcing result. First, the minimum quantity restriction is set at $q\left(P^{*}, R^{*}, A^{*}\right)$, i.e., the first-best output. Any retailers maximizing profits subject to this quantity constraint adjust retail prices and advertising until the marginal rate of substitution along an iso-profit contour just equals the relative change in retail price and advertising sufficient to meet the constrained demand. The question is whether Loschian or Nash retailers defined by their profit-maximizing behaviour and constrained by open entry and minimum wholesale transactions fulfill this substitution condition. The answer is immediately yes for Loschian firms and yes for Nash firms once they have been transformed to Loschian firms via CTD's.

Why is this? Consider the Loschian firms. Here there are no pecuniary externalities (and horizontal advertising externalities are absent by assumption $(\alpha=0))$. Forcing as a restraint does not involve the internalization of the vertical externality caused by the $\left(P_{w}-c\right)$ wedge. Even under the forcing constraint, the retailer continues to appropriate only a proportion of the benefits from either lowering price or raising advertising. However, the proportions of benefits from the price and advertising decisions of the retailer that accrue to the retail outlet are the same, namely $\left(P-P_{W}\right) /(P-C)$. The marginal rates of 
substitution between price and advertising, in the elicitation of consumer demand, are therefore the same for the non-integrated retailer as for the integrated firm. The forcing constraint simply pulls the level of the advertising and pricing decisions to the first-best level for the manufacturing. When the retailer satisfies the forcing constraint by lowering retail prices and increasing advertising, the externalities to the manufacturer on retail prices and advertising are exactly offsetting.

We demonstrate el sewhere (Mathewson and Winter 1982a) that retail price ceilings and minimum quantity restrictions without local advertising are theoretically symmetric instruments. (At one level, this is not a surprise with well-defined retail demand functions even if consumers are spatially separated.) However, price ceilings and forcing in the presence of local advertising are not symmetric. Price ceilings would alter the rate of substitution between retail price and advertising without inducing retail firms to sell at the appropriate output level, i.e., without inducing the first-best local advertising level. In this case, at the very least, we would expect forcing as opposed to price ceilings to be used in industries where local advertising (including sales personnel) is important, a condition which apparently holds for the automobile industry.

We have analyzed the incentives for vertical restraints or integration in the absence of advertising spillovers. Even in the absence of such spillovers, the spot market at the wholesale level is inadequate, but franchise fees or forcing alone (with CTD's if necessary) together with wholesale prices are sufficient restraints for the manufacturer to achieve the most profitable solution. We consider next the case of such inter-retailer externalities. 


\subsection{Sufficient Restraints: Spillovers}

In this section a (defined in (A7)) is strictly positive so that there are advertising spillovers across retail outlets. Informational free-riding by some economic agents (or equivalently, the non-appropriability of total benefits of information by those agents that incur the cost) is at the heart of many analyses of the inadequacy of spot-market contracts (e.g., Telser 1960).

The first consequence of the introduction of these informational spillovers is the failure of Proposition 2 and $3 . P_{w}$, franchise fees and CTD where required no longer constitute a sufficient set of instruments: If $P_{w}$ were set equal to $c$ to elicit a retail price of $P *$ (i.e., to make (9) identical to (12)), then the retail outlets no longer would set the first-best $A$, as the left-hand side of $(16)$ is less than the left-hand side of (17). In other words, while eliminating the $\left(P_{W}-c\right)$ wedge internalizes the vertical externality imposed by the retailer on the upstream manufacturer, it fails to capture the horizontal externality across retail outlets from informational spillovers. In this case, if advertising by any retail outlet (A) were increased, the franchise fees could be increased without violating the zero retail-profit condition on those other retailers who were the beneficiaries of the advertising spillover.

With advertising spillovers, the following propositions delineate the minimally sufficient sets of instruments. Any pair of the three instruments, resale price maintenance, franchise fees, and forcing is sufficient. 
Proposition 6: If retailer conjectures are non-Loschian or if there are information spillovers, resale price maintenance and franchise fees constitute a minimally sufficient set of restraints. The optimal wholesale price under these restraints is less than the cost of production.

Proof: Setting a retail price at $P *$ and letting $P_{W}$ and $G$ solve equations (7) or (16) (depending on the absence or presence of information spillovers) and (17) yields a set of instruments that elicits the optimal levels of retail advertising $\left(A^{*}\right)$ and market radius $\left(R^{*}\right)$. To show that $p^{*}$ can be maintained with a price floor, it suffices to show that $\pi_{p}^{R}<0$ at this equilibrium. From (14) and (15), with $\alpha>0$, $\left(P-P_{W}\right)>(P-C)$ so that $P_{W}<c$. From $(12)$ and $P_{W}<c$, the left-hand side of $(9)$ is negative and therefore, the left-hand side of $(6)$ is also negative. Thus $\pi_{p}^{R}<0$ at the optimum, whatever the conjectures, and $p *$ is maintained by the manufacturer via a price floor.

In this case, the manufacturer sets directly the first-best retail price $P *$ (as a price floor) and then sets $P_{W}$ to elicit the optimal local advertising from the retailer (with or without informational spillovers) and $G$, as usual, transfers rents back to the manufacturer to effect the optimal density of firms. The use of a price floor yields the one optimal retail price provided retailers have no incentive to raise their retail prices. To provide a sufficient incentive for retailers to advertise locally in the presence of retail informational spillovers, the manufacturer sets a wholesale price less than marginal production costs. In this case, with reduced wholesale prices, retailers advertising optimally at $A^{*}$ would only wish to lower and not raise their retail price from the price floor $p^{*}$, i.e., in fact, the price floor is an observed administered price. 
Proposition 7: If retailer conjectures are non-Loschian or if there are information spillovers, resale price maintenance and forcing are a minimally sufficient set of restraints.

Proof: Set the forcing constraint $\hat{q}=q\left(P^{\star}, R^{\star}, A^{\star}\right)$, set the retail price $P^{*}$ and set $P_{W}$ to satisfy the zero-profit condition (8). Given $P^{*}$, the retail outlet has no choice but to set at least $A^{*}$ to satisfy the forcing condition. (Further, it is straightforward to show that the retailer subject to forcing and $p *$ has no incentive to offer more advertising than $\left.A^{*}.\right)$ Consequently $\left(P^{*}, R^{\star}, A^{*}\right)$ satisfy the equilibrium conditions, zero retailer profits ( 8$), q=\hat{q}$, and $p=p *$. To show that $P *$ is maintained with a price floor, it is sufficient to show that $\partial \Pi^{R} / \partial P \mid(q=\hat{q})<0$ when evaluated at $\left(P^{\star}, R^{\star}, A^{\star}\right)$, i.e., that at $\left.\left(P^{*}, R^{*}, A^{*}\right),\left[\left(\partial \pi^{R} / \partial P\right) / \partial \pi^{R} / \partial A\right)\right]<[(\partial q / \partial P) /(\partial q / \partial A)]<0$. But this inequality was shown to hold in the proof of Proposition 5 for Nash retail conjectures. It is straightforward to extend this demonstration to the case of positive information spillovers with Nash retail conjectures. Next, for Loschian retail conjectures, $\partial q / \partial A$ is decreased by the presence of information spillovers. In the absence of spillovers, (22) holds; therefore, with information spillovers $-(q / b)>\left[\left(\partial q / \partial P_{j}\right) /\left(\partial q / \partial A_{j}\right)\right]$. From (21) (which holds even with information spillovers), it follows that in the presence of Loschian retail conjectures and information spillovers, $\left[\left(\partial \pi^{R} / \partial P\right) /\left(\partial \pi^{R} / \partial A\right)\right]<[(\partial q / \partial P) /(\partial q / \partial A)]$ evaluated at $\left(P^{*}, R^{\star}, A^{*}\right)$.

In this case, the manufacturer first sets a minimum wholesale transaction to each retailer equal to consumer demand at $\left(P^{*}, R^{*}, A^{*}\right)$, next sets the optimal retail price itself $\left(P^{*}\right)$, and finally sets $P_{W}$ to guarantee zero retailer profits at the optimal density of outlets. From the perspective 
of the individual retailer, there is no choice on advertising with $p *$ and $\hat{q}$ : To sell $\hat{q}$ at $P^{*}$, each retailer must advertise exactly $A^{*}$. Further, at $\left(q, P^{*}, R^{*}, A^{*}\right)$, retailers have a desire only to lower and not raise their retail prices so that the price is again administered through a floor. Why is this? In Proposition 4 on forcing alone with Loschian firms, the Loschian retailer in equilibrium even in the absence of quantity constraints, uses the correct mix of retail prices and advertising, this firm equates the marginal rate of substitution between prices and advertising along an iso-profit contour to the rate at which prices and advertising may be substituted to hold constant consumer demands. However, the marginal rates of substitution for Nash retailers are less than the market-determined (constant demand at $\hat{q}$ ) substitutability. At the forced volume $\hat{q}$, therefore, these retailers have a private incentive to lower retail prices and advertising. In the presence of local informational spillovers $(\alpha>0)$ where the marginal profitability of advertising appears to be still lower, retailers have an exacerbated incentive to decrease price and advertising margins. Therefore, the price floor (RPM) is binding.

Proposition 8: If retailer conjectures are non-Loschian or if there are informational spillovers, then franchising fees and forcing are a minimally sufficient set of restraints.

Proof: Set the forcing constraint $\hat{q}=q\left(P^{\star}, R^{\star}, A^{\star}\right)$. For each $P_{W^{\prime}}$, any desired $A$ results from setting $P$ in the constrained condition on retail prices and advertising given by (19). G is then set to satisfy the zero-profit condition (17) at $\left(P^{\star}, R^{\star}, A^{*}\right)$. Let $A(P)$ be defined by the forcing constraint at $R^{*}$ and note for future use that $\partial A(P) / \partial P>0$. 
To prove sufficiency of $G$ and $\hat{q}$, it is sufficient to show that there is a $P_{W}$ that elicits $P^{*}$. Denote the left-hand side of (19) as $M\left(A(P), P ; P{ }_{W}\right)$ and denote the right-hand side of $(19)$ as $Z$. Note that (19) is now written as $M\left(A(P), P ; P_{W}\right)=Z$. $Z$ does not depend on $P_{W}$ but does depend on the retailer conjectures and information spillovers (a). Consequently, note that (19) now written as $M\left(A(P), P ; P_{W}\right)=Z$ defines $P=P\left(P_{W}\right)$. Does the inverse of $P\left(P_{W}\right)$ exist?

From (15), it follows that (i) $\partial \pi^{R} / \partial P$ is increasing in $P_{W}$; (ii) $\partial \pi^{R} / \partial A$ is decreasing in $P_{W}$; (iii) $\partial \pi^{R} / \partial P$ is decreasing in $P$ and increasing in $A$; and (iv) $\partial \pi^{R} / \partial A$ is increasing in $P$, for $P$ less than the retailer's optimal $P$, and decreasing in $A$. From (i) and $(i i i), \partial M\left(A, P ; P_{W}\right) / \partial P_{W}>0$. Since the forcing constraint implies that $P$ is less than the retailer's optimal $P$ in the absence of a quantity constraint, ( $i i i)$ and (iv) above imply that $d M\left(A(P), P ; P_{W}\right) / d P<0$. Since $M\left(A(P), P ; P_{W}\right)$ is increasing in $P_{W}$ and decreasing in $P$, the previously defined solution (19), $P=P\left(P_{W}\right)$, has an inverse.

Therefore, setting $P_{W}^{*}=P_{W}\left(P^{*}\right)$ and $G$ appropriately will elicit $\left(P^{*}, R^{*}, A^{*}\right)$.

In this case, the manufacturer first sets a minimum wholesale transaction to each retailer equal to consumer demand at $\left(P^{*}, R^{*}, A^{*}\right)$. Even in light of this quantity constraint, non-Loschian firms - and, under informational spillovers, Loschian firms - fail to use the mix of retail prices and advertising that is in the profit-maximizing interests of the manufacturers. The manufacturer requires an additional instrument to correct this mix. In the presence of a quantity constraint, retailers equate their marginal rates of substitution along an iso-profit contour to the rate at 
which prices and advertising may be substituted to hold constant consumer demands. Changes in $P_{W}$ by the manufacturer alter the retailer's marginal rate of substitution between retail price and advertising until the appropriate retail price $\left(P^{*}\right)$ and advertising level $\left(A^{*}\right)$ are elicited. Then, franchise fees are set to collect rents and to yield zero retailer profits at the appropriate density of retail firms $\left(R^{\star}\right)$.

\section{Conclusions}

This paper develops a theory of efficient contracts in wholesale markets with a view to explain the use of vertical restraints by manufacturers. The results of the paper are easily summarized: Under conditions which are characteristic of many retail markets - fixed retail costs, open entry into the retail business, a spatial distribution of consumers, and a role for local advertising by retailers - spot markets fail to establish the correct incentives of the non-integrated retailer to realize joint profit maximization for the retailer and a manufacturer with market power. At the source of this failure are a set of potential non-appropriabilities: Retailer conjectures may bestow perceived horizontal pecuniary externalities on other retailers; informational spill-overs with consequent freeriding yield horizontal non-appropriabilities to other retailers; manufacturer market power, and consequent mark-up of wholesale prices over marginal production costs, yield vertical non-appropriabilities. All of these effects may be appropriately harmonized by alternative sets of vertical restrictions. The view that price restraints and territorial restraints can be alternative responses to particular incentive problems and that the existing asymetry in U.S. legislation on the practices is therefore inappropriate (Posner 1981) finds support in out analysis. ${ }^{12}$ In fact, under 
the ideal conditions of our model, the substitutability of alternative packages of instruments is perfect. This would not be the case, however, in the presence of monitoring or other transactions costs. A study of the relative use of each restraint option by manufacturers would require recognition of relative transactions costs, along the line of Williamson (1975). 


\section{Figure 1}

\section{Retail Market}

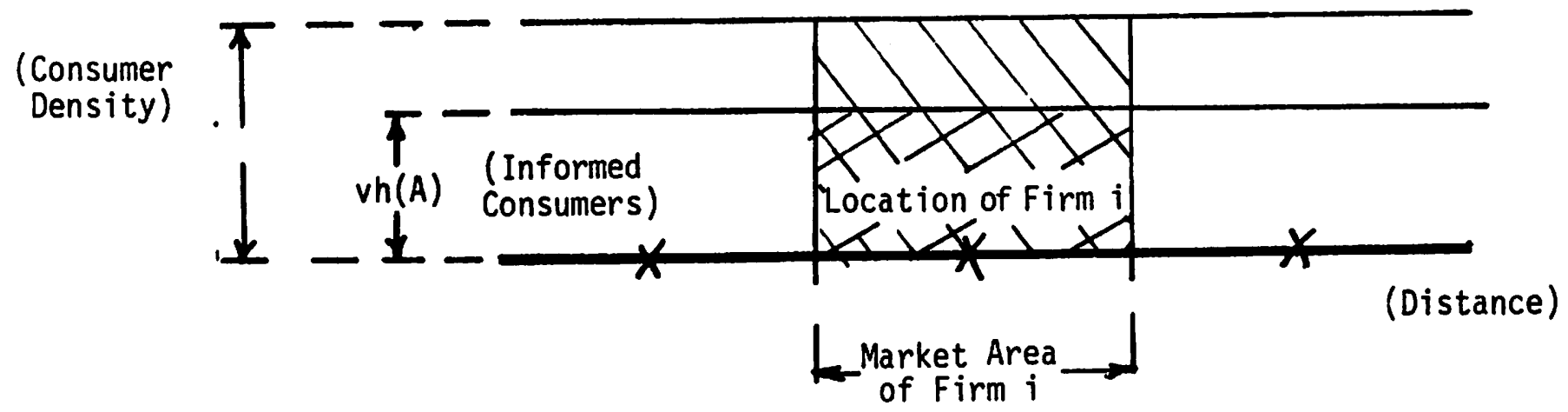


Table 1

Minimally Sufficient Sets of Instruments

\begin{tabular}{|c|c|c|c|}
\hline & \multicolumn{2}{|c|}{ Retailer Conjectures } \\
\hline & & Loschian & Nash or Non-Loschian \\
\hline \multirow[t]{2}{*}{$\begin{array}{c}\text { Absence } \\
\text { or } \\
\text { Presence } \\
\text { of } \\
\text { Local } \\
\text { Advertising } \\
\text { Spillovers }\end{array}$} & $\alpha=0$ & $\begin{array}{l}\text { Franchise Fees }(2)^{\star} \\
\text { Forcing (4) }\end{array}$ & $\begin{array}{l}\text { Closed Territory Distribution } \\
\text { and Franchise Fees (3) } \\
\text { Closed Territory Distribution } \\
\text { and Forcing (5) } \\
\text { Resale Price Maintenance } \\
\text { and Franchise Fees (6) } \\
\text { Resale Price Maintenance } \\
\text { and Forcing (7) } \\
\begin{array}{l}\text { Franchise Fees } \\
\text { and Forcing (8) }\end{array}\end{array}$ \\
\hline & $\alpha>0$ & \multicolumn{2}{|c|}{$\begin{array}{l}\text { Resale Price Maintenance and Franchise Fees (6) } \\
\text { Resale Price Maintenance and Forcing (7) } \\
\text { Franchise Fees and Forcing (8) }\end{array}$} \\
\hline
\end{tabular}

* Numbers in brackets refer to the number of the proposition in the text. 


\section{Footnotes}

1. Price ceilings are observed less frequently.

2. For example, in the U.S., RPM was illegal in most cases between 1911 and 1937. In 1937, the Miller-Tydings Act was passed, exempting RPM from the Sherman Act and the Federal Trade Commission Act, and in 1952 the McGuire Act required that retailers who did not sign an RPM agreement must nevertheless adhere to any such agreement signed by a producer and at least one seller. Subsequently, the provisions of the Miller-Tydings and the McGuire Act were repealed and today RPM is effectively illegal in the U.S. (although suggested list prices are not). In the same year that the McGuire Act was passed endorsing the practice in the U.S., Canada became the first country to ban RPM unconditionally. Then, in 1960, Canada's legislation was amended to allow certain exceptions. Britain's 1964 RPM Act established prima facie legislation against RPM; a producer charged with RPM has the burden of proving that the social benefits of his action exceed the disadvantages. West Germany's policy is similar to that of the U.S. and Japan allows RPM only in certain markets.

Legislation on vertical territorial restraints has followed a similar historical pattern in the U.S. Most recently, the Supreme Court in the Sylvania case (433 U.S.36 (1977)) altered the law on this practice from per se illegality to a (somewhat vague) rule of reason. Thus, vertical price restraints are currently per se illegal in the U.S. and territorial restraints are subject to a rule of reason.

3. See Capozza and Van Order (1978) for a concise analysis of spatial composition in two dimensions under the assumption of free entry. 
4. Therefore, downstream retailers have fixed production coefficients. While this el iminates one of the standard arguments for vertical integration, it is a reasonable specification for most retail outlets where the retail product does not permit substitution between the goods delivered by the manufacturer and other inputs. As a consequence, in our model, royalty fees are identical to the wholesale price. (For a discussion of royalty fees in a variable proportions model with Salop-type one-unit demand characteristics, see Dixit 1982.)

5. This occurs if consumers migrate to other retail markets; once informed of the product (or were outside their normal shopping area when informed) or if retailers at each location cannot target their advertising exclusively to their local market area.

6. For example, in the presence of informational externalities and high monitoring costs for the manufacturer, each retailer has an incentive to cheat on any local advertising targets set directly by the manufacturer. In actual markets, the substitution of direct local advertising may be inefficient. For example, local retailers may be capable of measuring local demand conditions more accurately than the manufacturer. This relative efficiency is outside our model.

7. In fact, conjectures in this paper may be viewed as Loschian and nonLoshchian (as opposed to Nash) as our comments on Nash generalize to non-Loschian conjectures.

8. The symetry assumptions and the two equilibrium concepts, Loschian competition and Nash or Hotelling-Smithies competition, are standard in the spatial competition. See, for example, Capozza and Van Order (1978). 
9. This is akin to the informational free-riding by discount houses in Telser's (1960) analysis of fair trade. However, the motivating force is not a variation in consumer search costs that facilitates a retail price distribution across dissimilar retail outlets (informing and non-informing). While such a horizontal externality is sufficient for the profitability of vertical restraints, it is not a necessary condition. The arguments for restraints need not rest alone on free-rider phenomena of the Telser type among retailers.

10. In fact, any non-co-operative game has such pecuniary externalities in conjectures. The real effect of these externalities is the failure to achieve jointly maximized profits (the co-operative solution).

11. White (1971: 224) estimates that U.S. dealers in 1966 spent $\$ 25$ per capita on local advertising but this figure excludes expenditures on local sales personnel.

12. The position that the vertical restraints analyzed in this paper can be welfare improving as well as efficiency enhancing is supported by our analysis in Mathewson and Winter (1982b). 


\section{References}

D.R. Capozza and R. Van Order (1978), "A Generalized Model of Spatial Competition", American Economic Review 68(5): 896-908.

R. Caves (1980), "Vertical Restraints as Integration by Contract: Evidence and Policy Implications", D.P. \#754, Harvard University.

R. Caves and W. Murphy (1976), "Franchising: Firms, Markets and Intangible Assets", Southern Economic Journal, 42: 572-86.

A. Dixit (2981), "Vertical Integration in a Monopolistically Competitive Industry", mimeo, Princeton University.

B.C. Eaton (1972), "Spatial Competition Revisited", Canadian Journal of Economics, 5: 268-278.

B.C. Eaton (1976), "Free Entry in One Dimensional Markets: Pure Profit and Multiple Equilibria", Journal of Regional Science, 16(1): 21-33.

B.C. Eaton and R.G. Lipsey (1976), "The Non-Uniqueness of Equilibrium in the Loschian Location Model ", American Economic Review, 66(1): 77-93.

B.C. Eaton and R.G. Lipsey (1978), "Freedom of Entry and the Existence of Pure Profits", Economic Journal, 88: 455-469.

M. Friedman (1976), Price Theory, Aldine Publishing Company.

J. Gould and L. Preston (1965), "Reseale Price Maintenance and Retail Outlets", Economica, 32: 302-331.

G.F. Mathewson and R.A. Winter (1981), "The Incentives for Resale Price Maintenance", W.P. \#8122, Institute for Policy Analysis, University of Toronto.

G.F. Mathewson and R.A. Winter (1982a), "Vertical Integration by Contractual Restraints in Spatial Markets", W.P. \#8205, Institute for Policy Analysis, University of Toronto.

G.F. Mathewson and R.A. Winter (1982b), "The Economics of Vertical Restraints in Distribution", paper presented at IEA Conference, Ottawa.

R.A. Posner (1981), "The Next Step in the Antitrust Treatment of Restricted Distribution: Per Se Legality", The University of Chicago Law Review, 48: 6-26.

S. Salop (1979), "Monopolistic Competition with Outside Goods", Bell Journal of Economics, 19(1): 141-156. 
$-35-$

F.M. Scherer (1980), Industrial Market Structure and Economic Performanse, Ind Edition, Rand MoRally.

J. Spengler (1950), "Vertical Integration and Antitrust Policy", Journal of Political Economy, 68: 347-352.

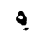

L.G. Terser (1960), "Why Should Manufacturers Want Fair Trade", Journal of Law and Economics, 3: 86-103.

R.G. Warren (1975), Antitrust in Theory and Practice, Grid Press.

L.J. White (1971), The Automobile Industry Since 1945, Harvard University Press.

O.E. Williamson (1975), Markets and Hierarchies: Analys is and Antitrust Implications, Free Press.

0.E. Williamson (1979), "Assessing Vertical Market Restrictions: Antitrust Ramifications of the Transaction Cost Approach", University of Pennsylvania Law Review, 127: 953-993.

8 
8202 A General Approach to Intertemporal and Interspatial Productivity Comparisons

M. Denny

M. Fuss

8203 Comparing the Efficiency of Firms: Canadian Telecommunications Companies

M. Denny

A. de Fontenay

M. Werner

$8204 \quad H o u s i n g$ Finance Contracts and the Non-Neutrality of Inflation

J.L. Carr

L.B. Smith

8205 Vertical Integration by Contractual

G.F. Mathewson

Restraints in Spatial Markets

R.A. Winter

8206 Strategic Timing and Pricing of a Substitute

N. Gallini

in a Cartelized Resource Market

T. Lewis

R. Ware

8207 The Rate of Time Preference and Dynamic Economic Analysis

L.G. Epstein

J.A. Hynes

8208 Stationary Cardinal Utility. and Optimal Growth Under Uncertainty

L.G. Epstein

8209 Bursting Bubbles: A Note on the Rationality of Hyperinflations in Optimizing Models

R.E.A. Farmer

8210 Implicit Contracts with Asymmetric Information and Bankruptcy: The Effect of

R.E.A. Farmer Interest Rates on Layoffs

8211 An Economic Theory of Vertical Restraints

G.F. Mathewson

R.A. Winter 